\section{Immunomagnetic DNA Aptamer Assay}

BioTechniques 30:290-295 (February 2001)

\begin{abstract}
DNA aptamers, oligonucleotides with antibody-like binding properties, are easy to manufacture and modify. As a class of molecules, they represent the biggest revolution to immunodiagnostics since the discovery of monoclonal antibodies. To demonstrate that DNA aptamers are versatile reagents for use as in vitro diagnostic tools, we developed a hybrid immunobead assay based on a $5^{\prime}$-biotinylated DNA thrombin aptamer (5'GGTTGGTGTGGTTGG-3') and an antithrombin antibody (EST-7). Our results show that the thrombin DNA aptamer is capable of binding to its target molecule under stringent in vitro assay conditions and at physiological concentrations. These findings also support the view that DNA aptamers have potential value as complementary reagents in diagnostic assays.
\end{abstract}

\section{INTRODUCTION}

Nucleic acid sequences can produce a wide variety of three-dimensional conformations. Some of these structural forms are able to interact with proteins and small molecules with high specificity and affinity. These sequences, comprising either doublestranded or single-stranded oligonucleotides, are called aptamers, based on the Latin word aptus, which means "to fit" (6). Using an efficient selection process, randomized oligonucleotide libraries can be rapidly screened for aptamers with the appropriate binding characteristics (12). This technology spawned the development of a new class of oligonucleotide therapeutic products and, although the interest among pharmaceutical companies continues to grow, there seems to be a reluctance to indulge the diagnostic potential of this technology. This may be due in part to the well-established use of monoclonal antibodies. Only recently is the literature beginning to reflect a growing emphasis on the potential for in vitro diagnostic use of aptamers
$(2,5,7,8,11)$. While it would be difficult to predict the replacement of all existing immunodiagnostic approaches, aptamers could play a complementary role. In some assays, aptamers may successfully replace established immunological reagents, while in others they may be more appropriate in combination as capture or tracer elements of an immuno-oligonucleotide hybrid assay format. To prove DNA aptamers are versatile reagents for future use as in vitro diagnostic tools, we developed an immuno-oligonucleotide hybrid assay based on one of the most characterized aptamers to date, which has previously been shown to inhibit human thrombin activity (1).

\section{MATERIALS AND METHODS}

\section{Thrombin Aptamer}

All aptamers to human thrombin were obtained through Life Technologies (Rockville, MD, USA) custom synthesis service, according to the 15mer G-quartet sequence $5^{\prime}$-GGTTGGTGTGGTTGG-3' defined in previous reports $(1,10,13)$. This aptamer is known to bind to the active site on thrombin, thus inhibiting its activity. The aptamers were biotinylated at the $5^{\prime}$ end of the sequence by the Life Technologies custom synthesis service. Aptamers were purchased with and without $5^{\prime}$ extension of one, two, four, or six additional thymidine residues acting as a spacer arm (T-tail). Aptamers were reconstituted in TE (10 mM Tris-HCl, $\mathrm{pH}$ 8.0, 1 mM EDTA) to obtain a $100-\mu \mathrm{M}$ solution and were stored at $-20^{\circ} \mathrm{C}$.

\section{Thrombin Standards}

Thrombin isolated from human plasma was obtained from Sigma (St. Louis, MO, USA) and was used diluted $(10,100$, or $1000 \mathrm{ng} / \mathrm{mL})$ in a high-protein assay buffer (A) containing $0.5 \%$ bovine serum albumin, $0.05 \%$ bovine IgG (Sigma-Aldrich, Oslo, Norway), $15 \mathrm{mg} / \mathrm{L}$ murine IgG1 (Roche Molecular Biochemicals, Mannheim, Germany), $50 \mathrm{mM}$ Tris- $\mathrm{HCl}, \mathrm{pH} 7.8,0.15$ $\mathrm{M} \mathrm{NaCl}, 0.001 \%$ Triton $^{\circledR} \mathrm{X}-100,0.1 \%$ Germall, $0.02 \mathrm{mM}$ diethylenetriaminepentaacetic acid (DTPA), and $0.005 \mathrm{~g} / \mathrm{L}$ tatrazine. The incorporation of bovine and murine IgGs prevents assay interference from heterophilic antibodies.

\section{Immuno-Oligonucleotide Hybrid Assay}

A variety of different assay strategies were tested (Table 1). The more traditional format using 96-well plates coated with the appropriate ligand (e.g., thrombin, aptamer, EST-7 antibody, and streptavidin) were notably unsuccessful. The following method incorporating immunomagnetic beads as the solid phase capture was the most appropriate strategy for this DNA aptamer.

Immunomagnetic beads of $280 \mathrm{~nm}$ particle size (Dynal, Oslo, Norway) were conjugated with sheep anti-mouse $\mathrm{Ig}$, according to the manufacturer's instructions, then incubated with the IgG1 anti- $\alpha$ thrombin monoclonal antibody, EST-7 (American Diagnostica, Greenwich, CT, USA). This antibody is known to react with an epitope distant from the active site and was unlikely to hinder the binding of the labeled aptamer. The resulting EST-7-coated beads were washed three times in a protein-free assay buffer (B) containing 50 $\mathrm{mM}$ Tris-HCl, pH 7.8, 0.05\% Tween $^{\circledR}$ 20 , and $0.1 \%$ Germall.

The immunofluorometric aptamer assay was performed in $11 \times 94 \mathrm{~mm}$ polyethylene tubes using a detachable magnetic rack system from Amersham Pharmacia Biotech (Little Chalfont, Bucks, UK). From the $100-\mu \mathrm{M}$ stock solution of aptamer, 5-60 $\mu \mathrm{L}$ were added to the thrombin diluted in 450 $\mu \mathrm{L}$ high-protein assay buffer (A). The mixture was incubated at $4^{\circ} \mathrm{C}$ for $2 \mathrm{~h}$ with vigorous shaking. After incubation, $100 \mu \mathrm{L}$ EST-7-coated magnetic beads $(5 \mathrm{mg} / \mathrm{mL})$ were added and incubated for another $30 \mathrm{~min}$ at room tem perature with vigorous shaking. The tubes were placed in the magnetic rack and incubated for 10 min before discarding the supernatant. Tubes were removed from the magnet, facilitating the resuspension of the beads, then $0.7 \mathrm{~mL}$ assay buffer $\mathrm{B}$ was added. Tubes were replaced in the magnetic rack and incubated for $5 \mathrm{~min}$. The wash cycle was repeated three times. After discarding the assay buffer from the final wash, 100 $\mu \mathrm{L}$ europium (Eu)-labeled streptavidin 


\section{Short Technical Reports}

Table 1. Different Assay Formats Tested for the Thrombin Aptamer

\begin{tabular}{|c|c|c|c|c|}
\hline $\begin{array}{l}\text { Assay } \\
\text { Format }\end{array}$ & $\begin{array}{c}\text { Primary Stage } \\
\text { (I) }\end{array}$ & $\begin{array}{l}\text { Secondary Stage } \\
\text { (II) }\end{array}$ & $\begin{array}{c}\text { Tertiary Stage } \\
\text { (III) }\end{array}$ & Detection \\
\hline 1 & 96-well + Thrombin & Aptamer & 125I-EST-7 & 125 \\
\hline 2 & 96-well + Aptamer & Thrombin & 125I-EST-7 & 125 \\
\hline 3 & 96-well + EST-7 & Thrombin + 5' B-Aptamer & Combined I + II & Eu-neutralite \\
\hline 4 & 96-well + Streptavidin +5' B-Aptamer & Thrombin & 125|-EST-7 & 125 \\
\hline 5 & SAM 450 + EST-7 & Thrombin + 5' B-Aptamer & Combined I + II & Eu-neutralite \\
\hline \multicolumn{5}{|c|}{$\begin{array}{l}\text { SAM } 450 \text {, sheep anti-mouse Ig coated paramagnetic particles }(450 \mathrm{~nm}) \text {. } \\
\text { EST-7, anti-thrombin monoclonal antibody. } \\
5^{\prime} \text { B-aptamer, } 5^{\prime} \text { biotinylated thrombin aptamer. }\end{array}$} \\
\hline
\end{tabular}

( $1 \mu \mathrm{g} / \mathrm{mL})$ were added and then incubated at room temperature for $30 \mathrm{~min}$ with vigorous shaking. The wash cycles were repeated six times before adding $200 \mu \mathrm{L}$ enhancing solution (Wallac, Turku, Finland), which releases the $\mathrm{Eu}^{+}$from the chelate. After incubating for $10 \mathrm{~min}$, the tubes were replaced in the magnetic rack for another 5 min before transferring $180 \mu \mathrm{L}$ from

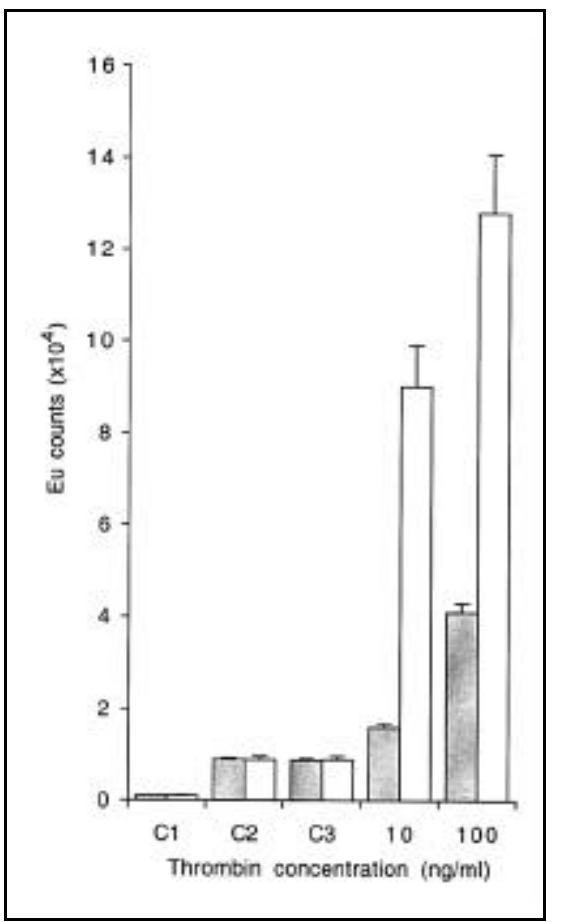

Figure 1. Graph illustrating the relative differences of thrombin detection in the immunometric aptamer assay for biotinylated aptamers comprising a 1-T spacer (shaded) or a 6-T spacer (unshaded). Aptamer concentration was $0.1 \mu \mathrm{M}$. Negative controls included: C1, no Eu-labeled streptavidin (neutralite); $\mathrm{C} 2$, no aptamer; and C3, no EST-7 antibody (irrelevant antibody control showed equivalent background to C3). each tube into a microplate. Plates were read by time-resolved fluorescence (1420 Multilabel Counter; Wallac). All assays were performed in triplicate. A variety of controls were tested to determine any interference from assay components or solid phases, including the omission of aptamer, thrombin, antibody, or Eu-neutralite from the assay. In addition, irrelevant antibody immunobeads were tested.

\section{RESULTS AND DISCUSSION}

Our approach, combining the use of aptamer and antibody in a hybrid immunofluorometric assay illustrates the versatility of DNA aptamers as diagnostic reagents. The strategy of using a magnetic bead solid phase in an immunofluorometric aptamer assay is novel and shows sensitivity for thrombin within physiological parameters (Figure 1). The total measuring error $(\% \mathrm{CV})$ of the assay was below $10 \%$ for throm bin concentrations up to $100 \mathrm{ng} / \mathrm{mL}$. Moreover, the stringent assay conditions and high-protein content support previous data indicating the aptamer binds with high affinity to thrombin (13). Interestingly, the sensitivity of our aptamer hybrid assay falls within the limits described in a recent report investigating thrombin levels as a prognostic marker in ovarian cancer patients (4).

The 15-mer anti-thrombin DNA aptamer is well documented in the literature. It has binding affinity in the low nanomolar range and readily binds to thrombin, inhibiting fibrin clot formation in vitro (1). The aptamer has been structurally characterized and has been shown to form a highly symmetrical Gquartet chair-like structure $(10,13)$.

In our studies, successful binding was only observed in a very specific assay format (Table 1, no. 5), suggesting the formation of the aptamer-thrombin complex in solution may be a prerequisite. That the comparable 96-well format assay (Table 1, no. 3) was unsuccessful further indicates that binding of this aptamer is sensitive to subtle variations in antigen presentation. One possible explanation could rest with the presentation of the EST-7 anti-thrombin antibody, which was directly bound to 96-well plates, while binding to beads was via an anti-mouse Ig. While this may reflect some general limitations in using aptamers in traditional 96-well assay formats, this feature may be more specific to the thrombin aptamer and/or aptamers with similar structural motifs. Indeed, nuclear magnetic resonance analysis has previously identified a specific G-quartet structure for this aptamer in solution (10), which in practice may be more susceptible to solid-phase coupling. Nevertheless, a recent study indicated that immobilization of the thrombin aptamer via a shorter six-atom spacer to silicate beads did not interfere with thrombin binding (9). Differences with the current study could be attributed to the different surface chemistries of the beads. Although there were no apparent differences in our assay performance for thrombin aptamers containing one, two, or four $\mathrm{T}$ residues in the $\mathrm{T}$-tail, the use of six $\mathrm{T}$ residues had a significant impact (Figure 2). It is not clear if these effects were the result of the proximity of biotin per se or if the length of the T-tail 


\section{Short Technical Reports}

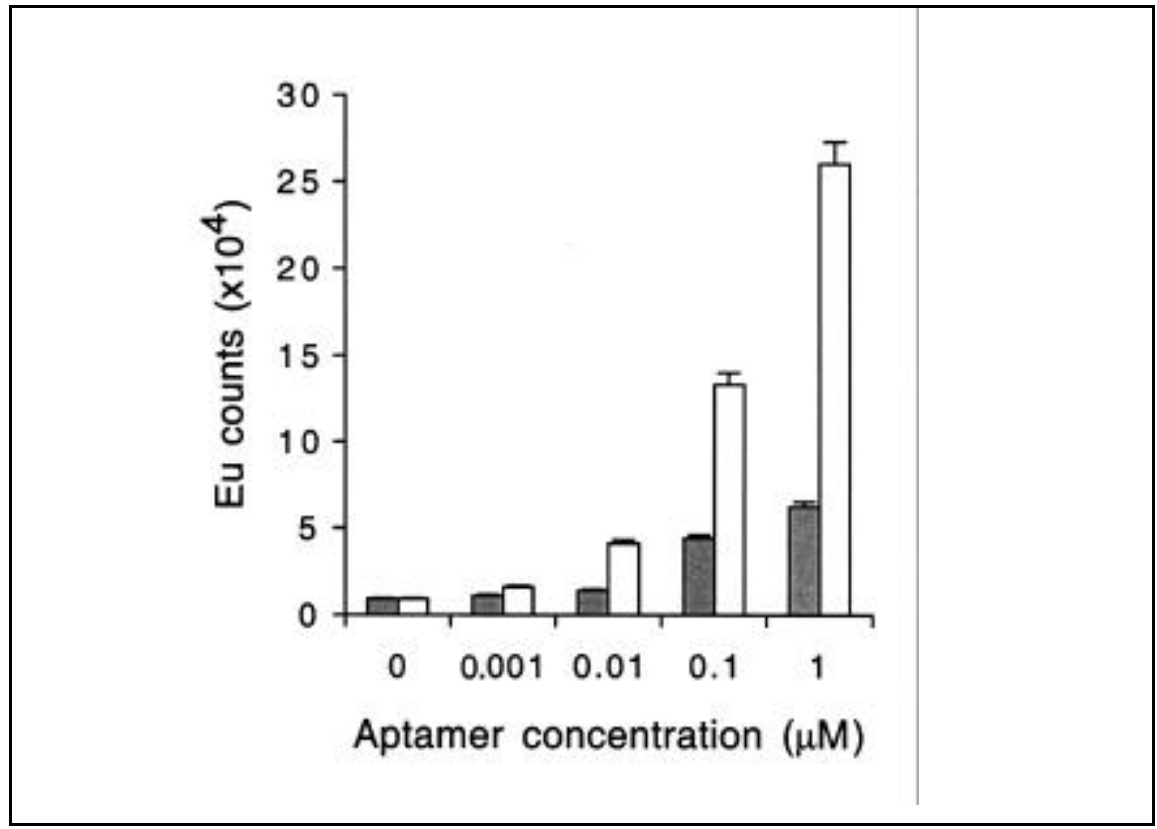

Figure 2. Graph showing differences in binding with increasing concentration of aptamer, for biotinylated aptamers containing a 1-T spacer (shaded) or a 6-T spacer (unshaded). Thrombin concentration was $100 \mathrm{ng} / \mathrm{mL}$. spacer contributed to a steric corruption of the aptamer's G-quartet structure. Similarly, these features may also be specific to the thrombin aptamer.

Aptamers have been used in a variety of in vitro studies including enzymelinked oligonucleotide assay (5), flow cytometry (3), and direct binding $(2,11)$. While this shows their versatility, our current findings also indicate that some aptamers may be more susceptible to assay conditions than their antibody counterparts or, indeed, other aptamers: the choice of solid phase used in an assay could significantly alter the aptamer conformation and hence the binding characteristics. Therefore, these factors need to be considered at an early stage in the selection process (12), such that all the characteristics of a given aptamer are suitable for its intended end use, not just for its binding affinity. Indeed, a promising development along these lines is the synthesis and selection of photo-cross- 
linkable aptamers that could be used as covalent capture reagents (2).

Our current findings demonstrate that the thrombin DNA aptamer is capable of binding to its target molecule under stringent in vitro assay conditions in the presence of high-protein and immunoglobulin concentration. This supports the view that DNA aptamers have potential value as complementary reagents in diagnostic assays.

\section{REFERENCES}

1.Bock, L.T., L.C. Griffin, J.A. Latham, E.H. Vermaas, and J.J. Toole. 1992. Selection of single-stranded DNA molecules that bind and inhibit human thrombin. Nature 355:564-566.

2.Brody, E.N., M.C. Willis, J.D. Smith, S.D. Jayasena, D. Zichi, and L. Gold. 1999. The use of aptamers in large arrays for molecular diagnostics. Mol. Diagn. 4:381-388.

3.Davis, K.A., B. Abrams, Y. Lin, and S.D. Jayasena. 1996. Use of high affinity DNA ligand in flow cytometry. Nucleic Acids. Res.
24:702-706.

4.Den Ouden, M., J.M.H. Ubachs, J.E.G.M. Stoot, and J.W.J. van Wersch. 1998. Throm bin-antithrombin III and D-dimer plasma levels in patients with benign or malignant ovarian tumours. Scand. J. Clin. Lab. Invest. 58:555-560.

5.Drolet, D.W., L. Moon-McDermott, and T.S. Romig. 1996. An enzyme-linked oligonuleotide assay. Nat. Biotechnol. 14:1021-1025.

6.Ellington, A. and J.W. Szostak. 1990. In vitro selection of RNA molecules that bind specific ligands. Nature 346:818-822.

7.Gold, L. 1995. Oligonucleotides as research, diagnostic, and therapeutic agents. J. Biol. Chem. 270:13581-13584.

8.Jayasena, S.D. 1999. Aptamers: an emerging class of molecules that rival antibodies in diagnostics. Clin. Chem. 45:1628-1650.

9.Lee, M. and D.R. Walt. 2000. A fiber-optic microarray biosensor using aptamers as receptors. Anal. Biochem. 282:142-146.

10.Macaya, R.F., P. Schultze, F.W. Smith, J.A. Roe, and J. Feigon. 1993. Thrombin-binding DNA aptamer forms a unimolecular quadruplex structure in solution. Proc. Natl. Acad. Sci. USA 90:3745-3749.

11.Osborne, S.E., L. Matsumura, and A.D. Ellington. 1997. Aptamers as therapeutic and diagnostic reagents: problems and prospects.
Curr. Opin. Chem. Biol. 1:5-9.

12. Tuerk, C. and L. Gold. 1990. Systematic evolution of ligands by exponential enrichment: RNA ligands to bacteriophage T4 DNA polymerase. Science 249:505-510.

13.Wang, K.E., S.H. Krawczyk, N. Bischofberger, S. Swaminathan, and P.H. Bolton. 1993. The tertiary structure of a DNA aptamer which binds to and inhibits thrombin determines activity. Biochemistry 32:11285-11292.

This research was supported by a grant from the Norwegian Cancer Society. Address correspondence to Dr. Philip D. Rye, Central Laboratory, Norwegian Radium Hospital, Ullernchausseen 70, Montebello, 0310 Oslo, Norway. e-mail: phil.rye @labmed.uio.no

Received 13 June 2000; accepted 25 September 2000.

Phil D. Rye and Kjell Nustad Norwegian Radium Hospital Oslo, Norway 